\title{
Transpancreatic Sphincterotomy: “I Don't Get No Respect”
}

\author{
John A. Martin ${ }^{1}$ \\ Accepted: 3 December 2020 / Published online: 2 February 2021 \\ (C) The Author(s), under exclusive licence to Springer Science+Business Media, LLC part of Springer Nature 2021
}

Sometimes, older technology and techniques deserve a second look, but the time has to be right. Consider electric cars, which have been around longer than automobiles powered by internal combustion engines [1,2], and at the turn of the twentieth century, there were nearly twice as many battery-powered electrics as internal combustion engine (ICE)-powered vehicles on American roads. But ICE vehicles, mostly due to their superior power and range, quickly overtook the electrics and, for the past 100 years, have been overwhelmingly dominant. Yet, a century later, electric cars are becoming all but commonplace and, due to their many superiorities, are predicted to surpass ICE autos rapidly to become the mainstream vehicles of the foreseeable future.

There are different reasons as to why the time can be right for a second look at a technology or a technique. Sometimes, a technology was not adequately developed, was too expensive, or was too complex for general acceptance. In other cases, society or culture simply was not ready for the idea. In yet other cases, there simply were not convincing data that a technique was safe enough to justify using, even though it was technically simpler to perform than some existing alternatives.

Why did electric cars fail to be commercial successes at the turn of the century? Rudimentary batteries that could not hold enough of a charge for adequate range or power, lack of adequate infrastructure for efficient battery recharging, and even advertising campaigns suggesting that clean electric cars were "ideal for women" all combined to undermine widespread adoption of electric cars [3]. Of course, today, these concerns are vanishing and a growing environmental consciousness is converging with accelerated improvement in battery technology and a proliferation of charging stations. Consequently, electric cars are gaining traction, with $>300,000$ sold in the USA in 2019.

John A. Martin

Martin.John3@mayo.edu

1 Division of Gastroenterology and Hepatology, Mayo Clinic, 200 First Street SW, Rochester, MN 55905, USA
While ERCP is likewise "old tech"- it is 52 years oldits popularity has thankfully never experienced a decline and remains a remarkably robust and essential medical technique and technology today. That is saying a lot for a medical technology that was first described by McCune in 1968 [4]. Less than two decades ago, some predicted that EUS, and then MRCP, would sideline ERCP. Instead, these new technologies simply soaked up some of the burdensome diagnostic work previously relegated to ERCP, such as diagnosing chronic pancreatitis and PSC, and advanced ERCP as an essential therapeutic tool.

In ERCP, as with most mature technologies, novel major advances are infrequent. Sometimes, however, older ideas, as was the case with electric vehicles, are worthy of a second look and old techniques may become new again. Such is the case for transpancreatic septotomy, a technique that has been revived as a salvage technique for difficult biliary cannulation for biliary obstruction and related pathology [5]. Although numerous noninvasive techniques have improved biliary cannulation success rates, including wire-guided biliary cannulation, sphincterotome-guided cannulation, double-wire cannulation, and cannulation beside a pancreatic stent [6-12], there are still times when invasive biliary access techniques, such as precut papillotomy using a needle knife or entry cut using a traction sphincterotome, are necessary. Alternative methods include suprapapillary fistulotomy and several rendezvous techniques. Nobody, or almost nobody, talks about transpancreatic septotomy (TPS), a technique described by John Goff in 1995 for difficult biliary access that uses a traction sphincterotome guided by a pancreatic guidewire to electrosurgically incise the pancreatic septum...until now. TPS has only rarely been taught during fellowship or post-training in recent years despite being introduced over two decades ago. To paraphrase the standup comedian Rodney Dangerfield (1921-2004), "I don't get no respect." TPS always seemed to be a bit of an outcast when it came to invasive entry techniques. Has the time finally come to give TPS some respect? In order to do so, there needs to be convincing data demonstrating that the technique is safe enough to justify using, even though it is technically simpler 
to perform than some existing alternatives. TPS never gained much traction perhaps because the concept of intentionally burning the pancreatic septum seemed to be begging for trouble, given sphincterotomy, pancreatic wire access, and pancreatic duct opacification are all independent risk factors for post-ERCP pancreatitis [13]. While there have been occasional series reporting its use, outcomes, and comparative utility, most reports have been descriptive, experiential, and retrospective and have included only a small number of patients [14]. It is upon this background that we congratulate Barakat et al. [15] for reporting the efficacy of TPS in a large cohort of patients in this issue of Digestive Diseases and Sciences. This study, while retrospective, augments the limited data available regarding this infrequently performed procedure. The authors emphasize that this technique is easily taught and readily adopted. Unlike needle-knife precut sphincterotomy (NKPS), which is a free-hand technique, TPS is wire-guided. Furthermore, with requisite pancreatic wire access, it lends itself to prophylactic pancreatic stent placement. As such, it is not surprising that the learning curve for TPS is less steep than that for NKPS. Nevertheless, the authors extrapolate that ERCP-trained endoscopists in the community setting-i.e., operators who are not trainees, but perform ERCP in lower volume, with lower frequency, and often without having undergone formal advanced endoscopy fellowship training-could therefore also adopt septotomy comparatively easily and safely, even in a "selflearned" fashion. This assertion is attributed to the authors' group of expert operators themselves deeming the technique to be easily adopted, and since their experiences demonstrate good outcomes and lower rates of pancreatitis than even their control group ERCP patients. This is arguably an overreaching deduction. While this inference on the part of the authors may make intuitive sense, it has not been tested as a concept by this study; the present series includes data from only one expert referral center, in a setting where learners of the technique invariably have immediate expert supervision or, at least, instant access to it. Until a study is performed in the community examining success rates and adverse events when septotomies are performed by non-advanced fellowship-trained endoscopists with lower ERCP volumes, it remains speculative as to whether this technique will be safe and effective in the community. Nevertheless, the hypothesis has merit since it brings attention to a little-known technique that is technically less demanding and perhaps a more easily taught alternative to needle-knife sphincterotomy-one which, as a bonus, lends itself to pancreatic stent placement as pancreatic duct wire access is the initial step in TPS.

This study produced a few unusual and potentially discordant results that deserve attention. First, there was no difference in post-ERCP pancreatitis (PEP) rates between difficult cannulation patients receiving or not receiving a pancreatic stent. This finding runs counter to most available data, and the practice of not routinely placing pancreatic stents after difficult cannulation contradicts the wisdom of available data and standards of practice $[16,17]$. In this series, pancreatic stents were placed in only $11 \%$ of TPS patients. The authors concede that their "nuanced" approach is to place pancreatic stents solely in TPS patients in whom the procedure was felt to be prolonged and more difficult. Their reasoning is that biliary access is rapid after TPS, obviating the need for prophylactic pancreatic duct stenting in most such cases. Furthermore, they conjecture that since TPS results in a partial pancreatic sphincterotomy, there will be less reduction in pancreatic duct outflow resistance due to edema than encountered after prolonged or challenging attempted cannulation by other means. The minority of patients that did receive a pancreatic stent were those in whom contrast drainage was subjectively delayed. Only a rigorous, comparative study performed prospectively will provide certainty as to whether a pancreatic stent should be inserted after TPS. Until then, omitting pancreatic stenting after TPS performed for difficult cannulation is probably not what one would want to promote with learners and lowvolume ERCP operators; poor outcomes resulting from such a practice may be difficult to defend. After all, if one already has guidewire access to the pancreatic duct anyway (as one always does in TPS), why not just go ahead and place a pancreatic stent, as is recommended by most guidelines? What is undeniably challenging is determining exactly how far into a difficult cannulation one should pull the trigger on opting to "cut one's way in." This decision point is, by any measure, still largely nuanced, given the absence of solid metrics derived from hard data.

Secondly, the control ERCP group actually had a higher PEP rate than the septotomy group (1\% vs. $2.3 \%$ ). This is somewhat counterintuitive, particularly when the endoscopists performing the series of procedures move quickly to TPS the moment cannulation becomes technically challenging. Not only did they find PEP rates following "Goff" septotomy to be comparable to those encountered with the double-wire technique and significantly lower than after NKPS; they found no significant difference in PEP rates between TPS patients and those who underwent standard cannulation, which they point out is consistent with outcomes from Goff's original series.

ERCP remains a powerful procedure for treatment of biliary disorders. Despite advances in the underlying technology, difficult biliary cannulation remains a significant challenge. When the going gets tough and cannulation is difficult, an old solution, now supported by the largest study to date, may be due for a second look. What still matters is getting the job done; without biliary access, all subsequent interventions such as stone extraction or stent placement are not possible. So, when the going gets tough-and cannulation is difficult — an old solution might be a worthy 
consideration, especially one which is suggested by a new, largest study to date to be not only effective, but also safer and more easily learned than existing alternatives. The time may finally be right to give John Goff's transpancreatic sphincterotomy a second look. A strong, methodical, prospective follow-up study may even make for an encore.

\section{Compliance with Ethical Standards}

Conflict of interest The author has no disclosures to make relevant to this paper.

\section{References}

1. Watson J, Correy S. The history of the electric car is longer than you might think. ABC Radio National, May 1, 2019. https://www. abc.net.au/news/2019-05-02/the-history-birth-death-resurrectionof-the-electric-car/11053928. Accessed March 6, 2020.

2. Kirsch DA. The Electric Vehicle and the Burden of History. New Brunswick: Rutgers University Press; 2000.

3. Chan CC. The rise and fall of electric vehicles in 1828-1930: lessons learned. Proc IEEE. 2013;101:206-212.

4. McCune WS, Shorb PE, Moscovitz H. Endoscopic cannulation of the ampulla of Vater: a preliminary report. Ann Surg. 1968; $167: 752-756$.

5. Goff JS. Common bile duct pre-cut sphincterotomy: transpancreatic sphincter approach. Gastrointest Endosc. 1995;41:502-505.

6. Tse F, Yuan Y, Moayyedi P, Leontiadis GI, Barkun AN. Doubleguidewire technique in difficult biliary cannulation for the prevention of post-ERCP pancreatitis: a systematic review and metaanalysis. Endoscopy. 2017;49:15-26.

7. Cortas GA, Mehta SN, Abraham NS, Barkun AN. Selective cannulation of the common bile duct: a prospective randomized trial comparing standard catheters with sphincterotomes. Gastrointest Endosc. 1999;50:775-779.
8. Rossos PG, Kortan P, Haber G. Selective common bile duct cannulation can be simplified by the use of a standard papillotome. Gastrointest Endosc. 1993;39:67-69.

9. Siegel JH, Pullano W. Two new methods for selective bile duct cannulation and sphincterotomy. Gastrointest Endosc. 1987;33:438-440.

10. Gyokeres T, Duhl J, Varsanyi M, Schwab R, Burai M, Pap A. Double guide wire placement for endoscopic pancreaticobiliary procedures. Endoscopy. 2003;35:95-96.

11. Yang MJ, Hwang JC, Byung MY, et al. Wire-guided cannulation over a pancreatic stent versus double guidewire technique in patients with difficult biliary cannulation. BMC Gastroenterol. 2015; $15: 150$.

12. Cote GA, Ansstas M, Pawa R, et al. Difficult biliary cannulation: use of physician-controlled wire-guided cannulation over a pancreatic duct stent to reduce the rate of precut sphincterotomy. Gastrointest Endosc. 2010;71:275-279.

13. Freeman ML, DiSario JA, Nelson DB, et al. Risk factors for postERCP pancreatitis: a prospective, multicenter study. Gastrointest Endosc. 2001;54:425.

14. Pecsi D, Farkas N, Hegyi P, et al. Transpancreatic sphincterotomy is effective and safe in expert hands on the short term. Dig Dis Sci. 2019;64:2429. https://doi.org/10.1007/s10620-019-05640-4.

15. Barakat MT, Girotra M, Huang RJ, et al. Goff septotomy is a safe and effective salvage biliary access technique following failed cannulation at ERCP. Dig Dis Sci. (Epub ahead of print). https://doi. org/10.1007/s10620-020-10.1007/s10620-020-06124-6.

16. Chandrasekhara V, Khashab MA, Muthusamy VR, et al. Adverse events associated with ERCP. Gastrointest Endosc. 2017;85:32-47.

17. Dumonceau J-M, Kapral C, Aabakken L, et al. ERCP-related adverse events: European Society of Gastrointestinal Endoscopy (ESGE) Guideline. Endoscopy. 2020;52:127-149.

Publisher's Note Springer Nature remains neutral with regard to jurisdictional claims in published maps and institutional affiliations. 